Doi: 10.22478/ufpb.1983-1579.2019v12n3.46179 http://periodicos.ufpb.br/ojs2/index.php

\title{
A FORMAÇÃO DE PROFESSORES DE ARTES VISUAIS NA REGIÃO CENTRO-OESTE: currículo e políticas
}

THE TRAINING OF VISUAL ARTS TEACHERS IN THE CENTRAL-WEST REGION: curriculum and policies

Vera Lucia Penzo Fernande

Resumo: Considerando as ações articuladas de pesquisa sobre os processos de formação de professores em artes visuais, realizadas pelo Observatório de Formação de Professores de Arte Visuais, identificamos a necessidade de mapear dados sobre os cursos de licenciatura nessa área de conhecimento, na Região Centro-Oeste, com o objetivo explicitar os impactos das políticas educacionais para a definição das estruturas curriculares dos cursos de formação de professores de Artes Visuais. Realizamos a coleta de informações disponíveis no sistema E-mec e nos sites de cada curso. A partir de uma base sócio-histórica, realizamos a análise exploratória e apresentamos dados quantitativos sobre as instituições de ensino que ofertam os cursos e sua categoria administrativa, ano de credenciamento e de criação do curso, modalidade de ensino, se presencial ou a distância, tempo para integralização. Especialmente a partir da análise das estruturas curriculares, consolidamos algumas reflexões, expressas nos eixos temáticos: a relação entre a formação específica e a formação pedagógica; as interfaces com outras áreas de conhecimento; a continuidade e o retorno da polivalência na formação de professores de arte; a preocupação com as tecnologias digitais. Os resultados apontam para o crescimento dos cursos ofertados na modalidade a distância e o fechamento de cursos presenciais, para a necessidade de valorização das práticas artísticas e para a atualização das estruturas curriculares, como forma de cumprimento da legislação vigente.

Palavras-chave: trabalho pedagógico; currículo; artes visuais; formação de professores.
Abstract: Taking into consideration the articulated research actions on the teacher education processes in the visual arts, carried out by the Visual Arts Teachers' Educational Observatory, we identified the need to map data on the degrees in this area of knowledge in the Midwest Region. The objective was to make explicit the impacts of educational policies for the definition of the curricular structures of the Visual Arts teacher training courses. We collect information available on the E-mec system and on the websites of each course. Based on a socio-historical basis, we conduct the exploratory analysis and present quantitative data on educational institutions that offer courses and their administrative category, year of accreditation and course creation, type of teaching, whether face-to-face or distance, time for payment. Using mostly the analysis of the curricular structures as a base, we consolidated some reflections, expressed in the thematic niches: the relation between the specific formation and the pedagogical formation; the interfaces with other areas of knowledge; the continuity and return of polyvalence in the formation of art teachers; the concern with digital technologies. The results point to the increase of courses offered in the distance modality and the closing of presential courses, to the need of valorizing the artistic practices and to the updating of the curricular structures, as a form of compliance of the current legislation.

Key-words: pedagogical work; curriculum; visual arts; teacher training.

\section{O COMEÇO DO ESTUDO}

Este artigo resulta da comunicação oral Cursos de artes visuais - licenciatura na região centro-oeste: currículo e políticas, apresentada em 2016, nos eventos XII Encontro do Grupo de Pesquisa Educação, Artes e Inclusão, I Encontro do Observatório da Formação de Professores de Arte e II Encontro da Rede

${ }^{1}$ Doutora em Educação pela Universidade Federal de Mato Grosso do Sul. Professora de Artes Visuais, na Universidade Federal de Mato Grosso do Sul. E-mail: vera.penzo@ufms.br. ORCID: http://orcid.org/0000-0002-9994-5500. 
Latino-Americana de Investigadores sobre a Formação de Professores de Arte (LAIFOPA), realizados conjuntamente no Centro de Artes da Universidade do Estado de Santa Catarina (UDESC), em 2016.

Nosso objetivo, então, era bastante singelo: apresentar dados quantitativos sobre os cursos de formação de professores de Artes Visuais na Região Centro-Oeste, fazendo um mapeamento que contribuísse com o levantamento de dados e atividades do Observatório de Formação de Professores de Arte. Tal objetivo havia sido definido no I Encontro da Rede LAIFOPA, em Santiago do Chile, em 2015 - ano em que passamos a integrar os dois grupos interinstitucionais de pesquisas sobre formação de professores de Arte.

Durante a apresentação e após amplas discussões que envolviam temáticas expressas no próprio título da comunicação, percebemos que nosso real objetivo estava longe de ser simples e apresentava-se como um grande desafio: explicitar os impactos das políticas educacionais para a definição do currículo dos cursos de formação de professores de Artes Visuais na região Centro-Oeste. Agora, neste artigo, tal desafio torna-se nosso objetivo.

É difícil definir o início da formação de professores de arte, mas ações mais sistematizadas tiveram início em espaços alternativos, por meio de cursos preparatórios propostos pela Escolinhas de Arte no Brasil, na década de 1940. Tais cursos recebem o nome de cursos intensivos de arte na educação. Segundo Rosa (2005, p. 33), "havia uma preocupação de preparar professores para atuarem com base na proposta educacional da livre expressão". O trabalho do professor consistia em fomentar a criatividade e a espontaneidade do aluno, e os currículos escolares também seguiam contornos bastantes livres, de acordo com os princípios da educação centrada no aluno.

Na década de 1970 com a obrigatoriedade da Educação Artística nos currículos escolares, definida pela lei $n^{\circ} 5692 / 1971$, intensifica-se a oferta desses cursos preparatórios.

A concepção de que a preparação de professores deve ocorrer em formação acadêmica de nível superior, impulsionou mudanças na legislação e os cursos de Educação Artística começam a ser criados, ofertados por universidades, de maneira a atender a necessidade de professores Educação Artística para atuar em escolas de $1^{\circ}$ e $2^{\circ}$ graus. Esses cursos receberam a herança deixada pelas Escolinhas de Arte e, conforme Rosa (2005, p. 33), "estimulado pelo fazer espontâneo, o desenvolvimento da criatividade ainda é enfatizado no currículo escolar como objetivo central do ensino de arte [...]”.

Os cursos de licenciatura em Educação Artística tinham uma característica polivalente, o professor era preparado para desenvolver atividades de expressão plástica, musical e teatral, com a justificativa de fornecer uma formação integral ao aluno. Os primeiros cursos eram de licenciatura curta - com duração de 2 anos. Em momento posterior, esses deixam de existir, sendo substituídos pelos de licenciaturas plenas, com 4 anos de duração, contudo, ainda com caráter polivalente e, para minimizar a formação superficial, são criadas habilitações específicas, principalmente em desenho, artes plásticas e música.

Uma mudança bastante significativa ocorre na década de 1990, quando os cursos de Educação Artística começam a ser questionados e migram para uma nova nomenclatura: Artes Visuais, Música, Teatro, Artes Cênicas, de acordo com as habilitações existentes. Alguns ainda mantiveram as habilitações, por exemplo o curso de Educação Artística, com habilitação em Artes Plásticas, passa a se chamar Artes Visuais, com habilitação em Artes Plásticas.

O questionamento é feito pelos professores de arte que, organizados em um movimento político, defendiam a qualidade dos processos de ensino e aprendizagem, apontando para a ineficiência da formação polivalente e lutando pela valorização da especialização do conhecimento.

Essa trajetória nos mostra que a formação de professores tanto é definida pelo currículo escolar, quanto também o define. Existindo conflitos e contradições que tangenciam questões econômicas, estéticas e culturais que, por sua vez, resultam em políticas e práticas sociais em contínua mudança e movimento. E nessa articulação, vamos seguindo uma trajetória da qual sobressai a defesa da formação específica do professor de arte e a busca pela superação dos ranços deixados pela Educação Artística, sobretudo a polivalência. 
Em tempos mais recentes a formação de professores na área de Arte abrange formação inicial, que ocorre em Instituições de Ensino Superior (IES), de caráter público ou privado, em cursos de graduação, presencial e/ou a distância, com o grau licenciatura, nas áreas específicas de Artes Visuais, Música, Artes Cênicas, Dança ou Teatro, entre outras áreas específicas, como por exemplo: Desenho, Cinema, etc. E a formação continuada é ofertada por diversas instituições, de caráter público ou privado, acontece por meio de palestras, congressos, encontros acadêmicos, seminários, formação em exercício, cursos de aperfeiçoamento, capacitação, cursos de pós-graduação lato sensu ou stricto sensu nas áreas específicas de Artes Visuais, Música, Artes Cênicas, Dança ou Teatro, entre outras áreas ou temáticas específicas.

Araújo (2009) mostra-nos que, no período de 1970 a 1979, foram criados no Brasil 39 cursos de Educação Artística, de licenciatura curta e/ou plena, com habilitação em Artes Plásticas. Desses, apenas um estava localizado na Região Centro-Oeste. Esse curso é o de Educação Artística, criado em 1977, na Universidade de Brasília (UnB), no Distrito Federal (DF). Assim, podemos datar o início da formação de professores de Arte na Região Centro-Oeste, no ano de 1977.

De fato, trata-se de uma região bastante peculiar no que se refere à pesquisa, à produção científica e à formação de professores, seja pelos aspectos históricos e culturais que a caracterizam, por abrigar a capital do Brasil, pela sua amplitude geográfica, pela economia centrada na agricultura e na pecuária, ou pela própria trajetória que constitui a produção científica no Brasil, a qual se concentra nas regiões Sul e Sudeste.

A título de exemplo, vez que a grandes maioria das pesquisa e produções acadêmicas brasileira (artigos, dissertações, teses, etc.) são oriundas de cursos de pós-graduação, destacamos que, do total de 384 Programas de Pós-Graduação existentes na Região Centro-Oeste ${ }^{2}$, temos apenas um Programa de Pós-graduação na área básica Arte, com área de concentração em Artes Visuais (PPGAV), localizado na UnB, e com uma linha de pesquisa: Educação em Artes Visuais. Entre as disciplinas do curso de Mestrado em Artes Visuais, temos as disciplinas Metodologia de pesquisa de educação em artes visuais; perspectivas críticas da educação em artes visuais; e Perspectivas críticas da educação em artes visuais 1 e $2.3^{3}$

A UnB também é uma das IES associadas à rede PROF-ARTES, programa de Mestrado Profissional (Stricto sensu) em Artes com área de concentração em Ensino de Artes, reconhecido pela Coordenação de Aperfeiçoamento de Pessoal de Nível Superior (CAPES) do Ministério da Educação (MEC)4.

Destacamos, ainda, a existências de grupos de pesquisa que, vinculados ou não à programas de pós-graduação, desenvolvem ou concentram pesquisas sobre o ensino de artes visuais. Na Região Centro-Oeste temos três grupos de pesquisa cadastrados no Diretório dos Grupos de Pesquisa no Brasil do Conselho Nacional de Desenvolvimento Científico e Tecnológico (DGP/CNPq) : $^{5}$ Grupo de Pesquisa Ensino e Aprendizagem em Artes Visuais (GPENAV), criado em 2012, na UFMS; e-Arte/Educação Crítica, na Universidade Federal de Goiás (UFG), criado em 2009; e Ciberarte-educação, UFG, criado em 2000. Hillesheim (2013) considera a existência de outros dois grupos de pesquisa em cultura visual.

Esse cenário nos mostra que poucas são as pesquisas realizadas sobre o ensino de arte na/a partir da Região Centro-Oeste e, mais raras ainda sobre a formação de professores de arte, por isso mesmo, ressaltamos a importância das ações do Observatório de Formação de Professores de Arte, vez que

A área de arte se dedica pouco, ou quase nada, à problemática pedagógica da formação de professores de arte, entendendo este como um tema mais voltado à educação. Já a área de educação, na maioria dos estudos, como os desenvolvidos por Gatti e Barreto (2009) ou mesmo por Shiroma (2010),

\footnotetext{
${ }^{2}$ Dados disponíveis em https://sucupira.capes.gov.br, acesso em maio de 2019.

${ }^{3}$ Dados disponíveis em http://www.ppgav.unb.br/, acesso em maio de 2019.

${ }^{4}$ Dados disponíveis em https://www.udesc.br/ceart/profartes, acesso em agosto de 2018.

${ }^{5}$ Dados disponíveis em http://lattes.cnpq.br/web/dgp, acesso em agosto de 2018.
} 
preocupa-se muito mais com a formação docente em geral e mesmo com a formação de professores pedagogos, de português e matemática, que numericamente ocupam maior parcela das preocupações entre os pesquisadores da área do que com a formação de professores de artes. Raríssimos estudos tocam no nome da disciplina, seja pela sua recente inserção no currículo escolar, seja pelo pequeno número de professores e créditos da disciplina na escola (FONSECA DA SILVA; BUJÁN, 2016, p. 29).

Essas poucas pesquisas assumem caráter pioneiro e buscam definir bases conceituais para/sobre a formação de professores de Arte. Dentre algumas delas destacamos o estudo realizado por Rosa (2005), apresentado no livro A Formação de professores de Arte: diversidade e complexidade pedagógica. A autora discute a complexidade da formação pedagógica dos professores de arte a partir da legislação educacional e do contexto escolar, no qual sobressaem os desafios de articular arte e educação, em especial no que tange às questões multiculturais e à tecnologia no processo de produção artística e na ação pedagógica, questões levantadas em período permeado por uma concepção da supremacia dos conteúdos específicos da área de arte em detrimento da formação pedagógica, e no qual se entendia que os estágios supervisionados eram os responsáveis pela formação de professores.

Gonçalves e Rebouças (2017) organizam uma coletânea de textos no livro intitulado Modos de ser professor de arte na contemporaneidade e, partindo da concepção de que investigações de práticas e docência no ensino superior e na educação básica, apontam as práticas instituídas nos cursos de formação em artes, nas escolas e em outros espaços educativos. Tal estudo apresenta uma diversidade de olhares, dentre os quais destacamos Frade (2017), que discute a formação docente na prática da arte relacional, Aguiar (2017), que aborda a questão da cultura na formação de professores de arte e Simões (2017), que explana sobre a formação do professor de arte na modalidade a distância.

Por outro lado, a publicação de Buján, Frade, Fonseca da Silva e Cohas (2018), fazem reflexões conceituais e exploram contextos latino-americanos. Seguindo essa mesma intenção Santinho, Bessa-Oliveira e Carvalho (2017), apresentam pesquisas locais em diálogo com produções nacionais e da América Latina, organizadas no livro Diversidade e Arte na Formação de Professores Docente, produzidas por pesquisadores de universidades públicas de Mato Grosso do Sul e de outros estados ou países.

Já Fernandes (2018) fez uma análise das alterações curriculares ocorridas do curso de Artes Visuais da Universidade Federal de Mato Grosso do Sul, nos anos de 2009 e 2014. Segundo a autora, tais alterações definiram novos rumos para o referido curso e para o perfil de formação de professores egressos desse curso, sobretudo pela efetiva quebra dos resquícios da polivalência, o que ocorreu por meio da revisão das bases epistemológicas da proposta curricular, além disso indica a forma com que as políticas educacionais interferem na formação de professores; a participação do corpo docente na proposição de alterações curriculares e a inserção de novas tecnologias na proposta pedagógica do curso.

Tais estudos nos levam a fazer reflexões sobre a formação de professores de arte como ação política,

Muito se tem discutido e escrito sobre a formação do professor. No entanto, ela ainda é pensada no âmbito da dimensão técnica ou do como ensinar, esquecendo-se que o como ensinar nem sempre vem acompanhado de reflexões sobre quem ensina, o que se ensina, por que e para que se ensina. Isto significa que as reflexões em torno da formação do professor exige uma abordagem da teoria e da prática educativa comprometida como acesso ao conhecimento artístico-cultural, cuja finalidade última é a formação de homens e mulheres capazes de enfrentar os desafios inerentes à relação, capital, trabalho, educação e de criar um projeto político-educativo comprometido com as transformações sociais e, por consequência, com uma nova educação não excludente (FONSECA DA SILVA; HILLSHEIM, 2014, p. 20). 
Essa concepção sobre formação de professores articula-se com a concepção de currículo como construção social historicamente configurado, e também com um percurso metodológico que busca uma imersão em determinadas práticas administrativas e às condições estruturais que lhe dão forma, seguindo os pressupostos de Gimeno Sacristán (2000). Destacamos ainda que o currículo é "sedimentado dentro de uma determinada trama cultural, política e social; carrega valores e pressupostos que precisam ser decifrados. Como construção social, está presente no sistema educativo [...]" (FERNANDES, 2018, p. 151).

É justamente nessas práticas administrativas e na organização de saberes que tangenciam formas de ser e pensar que situamos nosso olhar sobre as estruturas curriculares dos cursos de licenciatura em Artes Visuais da Região Centro-Oeste, buscando desvelar concepções, intencionalidades e direcionamento da formação de professores de artes.

\section{OS CURSOS DE LICENCIATURA EM ARTES VISUAIS NA REGIÃO CENTRO-OESTE}

Nesta seção apresentaremos informações qualitativas articuladas com questões quantitativas sobre os cursos de licenciatura em artes visuais existentes na Região Centro-Oeste, fazendo uma análise com base em uma abordagem sócio-histórica.

Inicialmente, fizemos levantamento de dados disponíveis no E-mec referentes à quantidade de cursos, ano de início, modalidade de ensino, se presencial ou a distância, quantidade de vagas e o tempo para integralização de cada curso. Posteriormente acessamos os sítios digitais de cada curso, buscando o histórico, a estrutura curricular e a localização. Para ambas as coletas temos 2016 como ano base.

Essas informações foram cuidadosamente sistematizadas e organizadas, e passaram por leituras e releituras que nos permitem apresentar características gerais dos cursos de licenciatura em Artes Visuais na Região Centro-oeste, conforme descreveremos a seguir.

Identificamos que a existência 17 cursos de licenciatura com a nomenclatura artes visuais ${ }^{6}$ na Região Centro-oeste, sendo 10 na modalidade presencial, e 7 na modalidade a distância, ofertados por 14 IES, sendo 4 são públicas estatais, 5 privadas com fins lucrativos e 5 privadas sem fins lucrativos. No caso das IES que ofertam cursos de licenciatura em artes visuais na modalidade a distância, as sedes estão localizadas nas regiões Sul e Sudeste.

O primeiro curso de formação de professores de arte, na modalidade presencial, em IES pública, é o da UnB, criado em 1977, com o nome de Educação Artística, com habilitação em Artes Plásticas. Posteriormente, a partir da extinção da nomenclatura Educação Artística, foram criados os cursos de licenciatura em Artes Plásticas, um criado em 1989 e outro em 1993.

O curso mais antigo em IES privada é presencial e foi criado em 1980, em Brasília, na Faculdade de Artes Dulcina de Moraes (FADM), com a denominação Educação Artística, com habilitação em Artes Plásticas. No sítio digital da FADM consta a nomenclatura Artes Visuais, mas em seu projeto pedagógico ainda se utiliza o nome Educação Artística.

Já o primeiro curso de licenciatura em artes visuais na modalidade a distância foi criado em 2007, na UnB. Os dois mais recentes foram criados no ano de 2015, um no Centro Universitário Internacional (UNINTER) e outro na Universidade Cruzeiro do Sul (UNICSUL).

O mais novo curso presencial de licenciatura em Artes Visuais foi criado em 2015, sendo ofertado pelo Instituto Federal de Goiás (IFG), em Goiânia.

A nomenclatura Educação Artística começa a cair em desuso no final da década de 1990, conforme já afirmado anteriormente, quando os cursos de Educação Artística com habilitação em artes

\footnotetext{
${ }^{6}$ Os dados do sistema E-mec informam que temos 4 cursos de Educação Artística, com habilitação e em Artes Plásticas e 1 curso com a denominação Artes Plásticas, na região Centro-Oeste. Não contamos estes cursos, porque selecionamos apenas os que recebem a nomenclatura Artes Visuais.
} 
plásticas passaram a ser chamados de Artes Visuais. Embora nem todos mantenham a antiga habilitação, apresentando-se com roupagem nova e, em alguns casos, com traços da polivalência.

Destacamos algumas particularidades referente à nomenclatura, como é o caso da UnB a qual destoa das demais IES, pois substitui o curso de Educação Artística, que até então constava como habilitação, pelo de Artes Plásticas. A outra, abrange uma questão administrativa, como é o caso do curso de Educação Artística, com habilitação em Artes Plásticas da UFMS, o curso teve início em 1981 e passa a ser Artes Visuais, no ano de 1999, mas não encontramos documentos oficiais que explicam a forma de mudança da nomenclatura.

No caso das IES que ofertam os 7 cursos de licenciatura em Artes Visuais na modalidade a distância, existem polos em mais de um Estado e no Distrito Federal, perfazendo um total de 200 polos distribuídos em vários municípios dos estados de Mato Grosso, Mato Grosso do Sul e Goiás e no Distrito Federal.

No caso dos 10 cursos de licenciatura em Artes Visuais na modalidade presencial, estão situados em cinco municípios dos estados de Mato Grosso do Sul, Goiás e no Distrito Federal. Observamos que no Estado de Mato Grosso não existe licenciatura em Artes Visuais na modalidade presencial (ver imagem 1).

Imagem 1: IES que ofertam cursos de licenciatura em Artes Visuais na Região Centro-Oeste, distribuídos por Estado, conforme localidade da IES e polos EAD

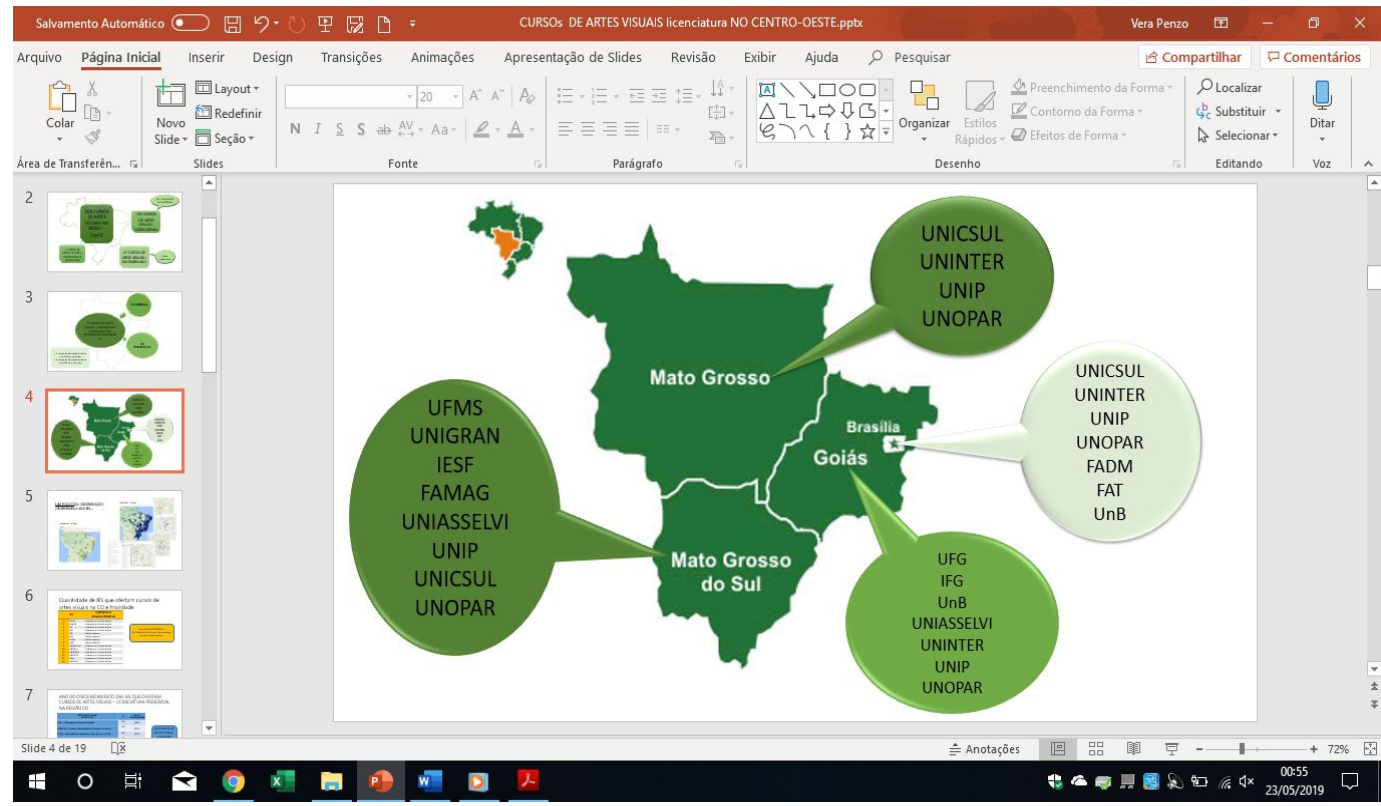

Fonte: arquivo da autora, elaborado com base nos dados E-mec -2016

Os 10 cursos licenciatura em artes visuais na modalidade presencial têm oferta total de 510 vagas; e os 10 cursos licenciatura em artes visuais na modalidade a distância têm oferta total de 49.946 vagas no Brasil.

No caso dos cursos licenciatura em artes visuais presenciais a quantidade de vagas é exata, variam de 30 a 200, por IES. Mas, dos cursos ofertados a distância não temos a mesma precisão, pois as vagas anunciadas pelas IES nos dados de credenciamento do curso no E-mec, variam de 60 a 46.900 vagas. Esse credenciamento não indica se essa quantidade está prevista para cada polo ou para o curso no Brasil todo, dessa maneira o total de 49.946 pode ser muito maior, pois apenas na Região Centro-Oeste temos 200 polos anunciados como existentes, nos 3 estados e no Distrito Federal, distribuídos entre as 7 IES que ofertam os cursos.

Analisando a carga horária para integralização temos 16 cursos com organização em semestres letivos, com 2 semestres ao ano, perfazendo um total de 6 semestres e 1 curso com organização em quadrimestre, o que poderia significar a conclusão em dois anos e meio. 
O tempo de integralização dos cursos presencias varia de 2.800 a 3.963 horas. Nas universidades, o tempo de duração é de 4 anos. Existe uma diferença entre o tempo de integralização e a carga horária ofertada. Assim, é relevante destacar que um curso de $2.800 \mathrm{~h} / \mathrm{a}$ na modalidade a distância é ofertado em 3 anos, e os presenciais são ofertados em 4 anos. Como é possível a concentração de tanta carga horária em tão pouco tempo? Esse dado pode ser alterado, considerando as prerrogativas das diretrizes para formação de professores (BRASIL, 2015).

\section{O QUE DIZEM AS ESTRUTURAS CURRICULARES}

Analisamos as estruturas curriculares dos 17 cursos de licenciatura em artes visuais, realizando uma leitura cuidadosa e detalhada, buscando articular essa leitura com o histórico do curso e com as ementas e bibliografias das disciplinas. Especialmente a partir da análise das estruturas curriculares, consolidamos algumas reflexões, expressas nos eixos temáticos: a relação entre a formação específica e a formação pedagógica; as interfaces com outras áreas de conhecimento; a continuidade e o retorno da polivalência na formação de professores de arte; a preocupação com as tecnologias digitais.

Cada um desses eixos temáticos abrange questões que se articulam e evidenciam os rumos da formação de professores de artes visuais na Região Centro-Oeste, conforme veremos nas seções abaixo.

\subsection{A relação entre a formação específica e a formação pedagógica}

Nossos estudos apontam a existência de um grande embate em torno da composição das estruturas curriculares que, em última instância, consolidam ideologias, epistemologias de conhecimento. As disciplinas listadas nas estruturas curriculares pela forma com que se apresentam, deixam evidentes uma concepção de arte, de cultura e de sociedade. Nesse cenário sobressai uma disputa entre a formação específica e a formação pedagógica.

A formação de professores de artes no âmbito universitário apresenta, desse modo, uma grande heterogeneidade (BUJÁN, 2013) que está plenamente vinculada com as culturas institucionais e que se manifesta claramente nos modos em que estão compostas e organizadas as matrizes curriculares de cada um dos cursos, nos modos em que são priorizadas algumas perspectivas e domínios disciplinares e, finalmente, na distribuição da carga horária em áreas de formação geral e específica da formação docente e das linguagens artísticas. (FONSECA DA SILVA; BUJÁN, 2016, p. 49)

Os estudos de Rosa (2005) indicam que desde a década de 1990 existia uma ideia, bastante comum nos cursos de licenciatura, de que a formação de professores acontece em disciplinas de estágio supervisionado obrigatório. Isso pode ser explicado pelo fato de terem sido constituídos a partir de cursos de formação de artistas, que primavam pela formação em ateliês. Então, parece quase natural entender que a formação de professores deve ser oriunda de uma atividade prática.

Essa, de fato, é uma concepção que podemos demarcar como a mais primeva sobre formação do professor: a valorização da atividade prática, por meio da aprendizagem por imitação do mestre no seu lócus de formação, como aconteciam nas guildas ou nas corporações de artes e ofícios ou nas academias de belas artes. Embora tenhamos experiências que demonstram outra forma de compreensão dessa realidade, como é o caso dos cursos de licenciatura e bacharelado em Artes Visuais da UFMS. Quando o curso ainda recebia o nome licenciatura em Educação Artística deu condições de existência ao Bacharelado em Educação Artística, em 1981 - um caso para ser estudado com maior profundidade, com certeza.

A valorização das atividades práticas pode ser identificada, também, na formação específica e evidenciada na oferta de disciplinas de Gravura, Pintura, Escultura, Desenho, Escultura, Cerâmica, História em Quadrinhos, Modelagem, Cinema, Vídeo, Fotografia, entre outras. 
Essa valorização é mais forte nos cursos presencias de licenciatura de artes visuais de IES públicas. Isso pode ser explicado pelo tempo de existência do curso, pela manutenção de uma tradição artística, pela concepção de arte que as definem, tanto como disciplinas quanto como prática artística. De fato, quase todas as disciplinas listadas acima são encontradas nas estruturas curriculares dos cursos.

No caso dos cursos de licenciatura em artes visuais na modalidade a distância, tais práticas artísticas aparecem isoladamente, com oferta de uma ou outra disciplina, geralmente o Desenho e/ou a Pintura. Não sendo possível identificar o motivo, se pela facilidade de material ou pela disponibilidade de acesso a laboratórios ou ateliês, disponíveis nos polos. De fato, a prática artística não está presente de maneira consistente nos cursos na modalidade a distância.

Em que pese a concepção de que a formação profissional se dá no âmbito da atividade prática, observamos que algumas estruturas curriculares apresentam um equilíbrio entre as disciplinas de formação específica e as disciplinas de formação pedagógica, tanto na quantidade de carga horária, quanto na forma de compreensão da relevância de cada uma delas para a definição do perfil do egresso.

Podemos afirmar que a visão de que a formação de professores ocorre apenas no âmbito das disciplinas de estágio ou de práticas de ensino está, em certa medida, superada, vez que se anuncia, no caso das IES públicas, uma preocupação com a articulação entre teoria e prática. Resta uma certa dúvida sobre a complexidade da formação profissional, nos demais casos.

\subsection{As interfaces com outras áreas de conhecimento}

Nessa categoria destacamos uma compreensão sobre o ensino de arte, como área de conhecimento, como campo de estudos aplicados. De fato, essa é uma abordagem um tanto polêmica e encontra eco nas discussões sobre a didática, ou ensino de [...]. A defesa do ensino de arte como uma área específica de conhecimento, vinculado à didática, ainda está em construção, e vem se consolidando ao longo da sua própria trajetória e constituição histórica. Nesse caso, a teoria da arte, as poéticas artísticas e concepções pedagógicas são seus elementos fundantes. Essa concepção e trajetória ocorre de maneira híbrida e interdisciplinar, em diálogo com outras áreas de conhecimento, como é o caso de antropologia, sociologia, pedagogia, psicologia, filosofia, entre outras.

Isso fica evidente na apresentação de disciplinas obrigatórias e específicas dos cursos em análise, como é o caso de disciplinas Arte e Antropologia, Estudos etnográficos, Folclore e Cultura Brasileira, Cultura Brasileira e Interculturalidade, Antropologia, Arte e Educação, no campo da Antropologia e estudos culturais, por exemplo.

No caso da Psicologia seus pressupostos estão representados nas disciplinas de Psicologia e Educação, Psicologia do Desenvolvimento e da Aprendizagem, Psicologia da Educação, Psicologia e a construção do conhecimento, ou ainda nos próprios princípios e fundamentos da arte, na disciplina Psicologia da Arte e da Forma.

O diálogo com as teorias pedagógicas coloca a Educação como uma das principais áreas de conhecimento que estruturam as licenciaturas. Tal questão está associada à história da criação de curso de formação de professores e da organização dos estudos e práticas relativos aos conhecimentos específicos das áreas de conhecimento. A didática apresenta-se como a linha norteadora de muitos projetos de formação de professores, além de se configurar objetivamente na disciplina Fundamentos de Didática. Além da didática identificamos a existência de outras disciplinas como Filosofia da educação e pensamento pedagógico, História da educação, Organização do trabalho pedagógico, Filosofia geral e da educação, Pensamento Pedagógico e a Construção da escola, Didática, Fundamentos de Didática ou das Políticas Educacionais. É fato que muitas vezes são colocadas como disciplina nas estruturas curriculares por determinação legal, como forma de atender aos pressupostos das DCN, artigo 13, parágrafo $2^{\circ}$,

Os cursos de formação deverão garantir nos currículos conteúdos específicos da respectiva área de conhecimento ou interdisciplinares, seus fundamentos e metodologias, bem como conteúdos relacionados aos fundamentos da educação, formação na área de políticas públicas e gestão da educação, seus fundamentos e metodologias, direitos humanos, diversidades étnico-racial, de 
gênero, sexual, religiosa, de faixa geracional, Língua Brasileira de Sinais (Libras), educação especial e direitos educacionais de adolescentes e jovens em cumprimento de medidas socioeducativas (BRASIL, 2015).

Essas áreas de conhecimento definem e consolidam disciplinas, evidenciando o caráter interdisciplinar dos cursos de formação de professores de artes visuais, seja por força de lei ou por clareza do caráter interdisciplinar da própria arte. Por outro lado, as áreas de conhecimento parecem balizar os fundamentos dos Projetos Pedagógicos de Cursos, e para isso seria importante fazer um estudo para além das estruturas curriculares, para que tal informação fosse comprovada.

Parece haver uma disposição dos cursos na modalidade a distância em não inserir muitas disciplinas nas suas estruturas curriculares, o que se verifica na apresentação de uma listagem básica de disciplinas. Causa curiosidade não haver disciplinas de educação das relações étnico raciais, por exemplo.

As IES públicas são mais ousadas e ressignificam e/ou redimensionam os termos legais, ampliando os horizontes de compreensão conceitual sobre as terminologias expressas nos termos legais. Assumem autonomia e gestão sobre os conhecimentos que visam articular em suas estruturas curriculares.

\subsection{A continuidade e o retorno da polivalência no ensino de artes visuais}

Algumas IES apresentam uma estrutura curricular polivalente, como é o caso dos cursos de Artes visuais da FADM, do Centro Universitário Leonardo da Vinci (UNIASSELVI), da Faculdade Anhanguera de Taguatinga (FAT) e da Universidade Norte do Paraná (UNOPAR). O caso da FAT e da UNOPAR causam preocupação devido à abrangência territorial das IES credenciadas, pois possuem polos em vários municípios de vários estados, abrangendo todo o território brasileiro, com a indicação de grande número de vagas disponíveis.

As outras IES que apresentam uma formação não polivalente em Artes Visuais são a Faculdades Magsul (FAMAG), a Universidade Federal de Goiás (UFG), o IFG, a UFMS, a UnB, Centro Universitário da Grande Dourados (Unigram), a Universidade Paulista (UNIP), a UNICSUL e o Instituto de Ensino Superior da Funlec (IESF). A UnB, em especial, apresenta disciplinas optativas em teatro, música em dança, sendo facultado ao aluno a escolha.

A existência dos princípios polivalentes ou ainda de uma formação vinculados aos princípios tecnicistas da década de 1970, se fazem presentes em disciplinas dentre as quais destacamos: Desenho geométrico, Folclore brasileiro, Oficina básica de dança, Oficina básica de música, Educação musical, Artes cênicas, Técnicas de expressão vocal, História do teatro I e II, Prática de canto I e II etc.

O que fica evidente é a força das IES públicas federais e privadas, que mantém a formação em Artes Visuais, de caráter não polivalente, compartilhando de uma defesa da especialização do conhecimento, fazendo ecoar o teor político da formação de professores, comprometidas com a qualidade do ensino de arte.

O tema da formação polivalente é objeto de reflexão nos dois países, assim como a formação aligeirada e funcional, propiciada nos institutos de educação, principalmente nos de gestão privada, exigindo que os professores se organizem para reivindicar seus direitos (FONSECA DA SILVA; BUJÁN, 2016, p. 50).

A continuidade da polivalência pode estar associada às características do corpo docente do curso, que ainda conta com discentes oriundos de uma formação polivalente, formando professores em contextos mais atuais.

Muitos cursos foram criados recentemente e, por isso, podem apresentar uma preocupação em atender às demandas do mercado e, como forma de deixar seus currículos mais atrativos, desrespeitam 
as pesquisas sobre arte, ensino de arte ou sobre a formação de professores. Não descartamos a intenção em favorecer a contenção de recursos para a contratação de professores.

Registramos ainda disciplinas como Arte e Educação Ambiental, Meio ambiente, arte e sociedade, Educação ambiental, Projeto de pesquisa interdisciplinar, Projeto interdisciplinar, Artes visuais integrada, Projeto interdisciplinar de ensino e aprendizagem, Atuação junto ao Idoso, Educação inclusiva, LIBRAS, Relações étnico-raciais e afrodescendência. Tais disciplinas visam atender às prerrogativas legais sobre questões do caráter interdisciplinar do currículo, lei do idoso ou sobre a educação ambiental e sustentabilidade, de maneira bastante direta. Caberia fazer um estudo mais aprofundado sobre as ementas destas disciplinas.

\subsection{A preocupação com as tecnologias digitais}

Observamos que existem disciplinas que apontam para a preocupação com as tecnologias digitais que dão sustentação às poéticas artísticas contemporâneas ou ao próprio trabalho pedagógico e, também como forma de evidenciar o atendimento aos pressupostos legais.

Assim, a valorização e ênfase nas poéticas artísticas contemporâneas podem ser identificadas nas disciplinas de Fotografia, Vídeo, Fotografia e vídeo, Arte e tecnologia, Laboratório de Arte e tecnologia, Produção artística visual nas novas mídias, Computação gráfica e ilustração, Linguagens contemporâneas: vídeo e performance, por exemplo. Dessa forma, notamos a preocupação em que o currículo dos cursos contemple as poéticas de vanguarda e o uso das tecnologias digitais nas práticas artísticas.

A valorização das tecnologias digitais no trabalho pedagógico pode ser evidenciada, por meio da compreensão da necessidade de inserção das mídias digitais como recurso metodológico, contribuindo para que o professor tenha acesso às múltiplas possibilidades de uso de softwares, redes sociais, programa de edição de imagem, etc. Isso pode ser evidenciado em disciplinas como Multimídia e educação, Educação e tecnologia, Arte e tecnologia, Tecnologias contemporâneas na escola, Arte educação e tecnologias, Museus virtuais, Projeto design educacional, Tecnologia da imagem, Marketing pessoal, entre outras.

Observa-se que os cursos de formação de professores a distância apresentam como grande diferencial dos seus currículos a disciplinas de Arte e Tecnologia, apresentando uma vertente mais voltada para as poéticas digitais e para a arte contemporânea.

\section{CONSIDERAÇÕES FINAIS}

Nosso propósito inicial consistia em mapear dados sobre os cursos de licenciatura de artes visuais, na Região Centro-Oeste os quais apresentamos, em linhas gerais, neste artigo. Mas, para além deste propósito inicial, que nos mostra a quantidade de cursos, IES, vagas, carga horária ou tempo de existência, buscamos tratar desses dados como informações que contribuíssem para explicitar os impactos das políticas educacionais para a definição das estruturas curriculares dos cursos de formação de professores de Artes Visuais.

De fato, esse objetivo é auspicioso e, dentro dos limites deste texto, apresentamos alguns resultados que mostram o quanto a formação de professores interfere e no currículo do ensino superior, sendo ambos balizados e determinados por políticas educacionais, em constante diálogo com demandas sociais e culturais.

Dentre os dados apresentados, cabe destacar o crescimento de cursos na modalidade a distância, tomando como referência o ano de 2007, quando tínhamos apenas um curso e, em 2016 o total passa a 7 cursos, em 200 polos. Esse crescimento pode ter impactado nos cursos presenciais da FAMAG e do IESF que já não estavam mais abrindo novas turmas, desde os anos de 2015 e 2016.

O questionamento sobre a valorização das práticas artísticas ou de cursos que seguem o modelo de aulas em ateliês, acabam por favorecer os discursos que apregoam uma formação aligeirada e baseada em manuais instrucionais de formação de professores, distanciados da relação com as tradições e/ou conhecimentos artísticos e estéticos. 
Mesmo sem condições de fazer uma análise mais aprofundada sobre as mudanças e alterações nas estruturas curriculares, podemos afirmar que existe uma grande preocupação dos cursos em atender as prerrogativas legais, seja para garantir o reconhecimento dos cursos ou como forma de evidenciar suas particularidades e características locais.

Atender aos pressupostos legais pode significar uma ação mecânica, seguir uma espécie de check list do que um curso precisa ter para ser aprovado pelo MEC, mas pode representar também a possibilidade de que questões atuais sejam inseridas nos currículos do ensino superior.

Obviamente que a qualidade da formação do professor não está necessariamente vinculada ao cumprimento dos pressupostos legais. Embora entendamos que seguir e atender às diretrizes curriculares da educação básica, do ensino fundamental, do ensino médio, da educação especial, da formação de professores, dos cursos de graduação em artes visuais, da educação das relações étnico-raciais etc., possam definir mudanças significativas no perfil de egresso.

A conciliação de tantas forças e interesses contidos nas políticas educacionais e curriculares podem ofuscar as particularidades culturais instituídas localmente, ou ainda, podem ser redimensionadas a partir dessas particularidades. Essa conciliação é o que legitima as propostas curriculares dos cursos de formação de professores de artes visuais.

As políticas educacionais, de alguma maneira, normatizam e regulamentam o trabalho do professor, mas de fato é preciso de ações conjuntas para que efetivamente aconteçam. Nesse sentido, Saviani nos alerta, que uma proposta educacional precisa vir acompanhada de uma proposta orçamentária, pois a inserção de conteúdo ou disciplinas, em última instância necessita de força de trabalho e de recursos materiais.

As políticas educacionais, segundo Fernandes (2018, p. 161), assumem uma forma impositiva, interferindo e definindo as alterações curriculares nos cursos de formação de professores, mas "por outro lado podem contribuir para a ampliação da consciência sobre o que significa a formação de professores e o trabalho pedagógico do professor de artes visuais".

A formação de professores com uma perspectiva polivalente está focando o mercado de trabalho e seguindo os princípios de uma economia neoliberal que busca otimizar os recursos humanos, diminuindo custos para os empregadores.

Se temos um discurso que valoriza a formação polivalente até mesmo entre os docentes, formados na concepção da Educação Artística ou que compreendem que podem ministrar conteúdos de forma aligeirada e superficial, também temos propostas curriculares que propiciam a valorização de tal concepção, mesmo que isso signifique não considerar os avanços e a defesa da especialização do conhecimento, como pauta para a definição dos atuais dos currículos acadêmicos de formação de professores.

Também é polêmica a forma com que a formação de professores está associada a interesses comerciais, com cursos que são enaltecidos por estratégias de marketing, ainda mais pelo fato de as IES de educação a distância utilizarem-se do termo universidade, como nome fantasia, quando na verdade são instituições de ensino superior ou institutos de educação. Ou ainda a forma de divulgação dos seus cursos, com propaganda oferecendo facilidades de pagamento, de acesso, de processo seletivo personalizado, com poucas aulas e leituras reduzidas.

Enfim, nossos estudos assumem caráter preliminar, vez que, embora tenhamos nos debruçado para realizar uma análise consistente, temos clareza de que nosso olhar é de sobrevoo e de que muitas e muitas outras questões podem ser aprofundadas, por exemplo: Quantos alunos estão matriculados efetivamente nos cursos de licenciatura em artes visuais na modalidade a distância? Como a identidade profissional se define a partir de uma proposta curricular e das políticas educacionais?

\section{REFERÊNCIAS}


AGUIAR, Maria Pêgo. A questão da cultura na formação de professores de Artes. In: GONÇALVES, Maria Gorete Dadalto; REBOUÇAS, Moema Martins. Modos de ser professores de Arte na contemporaneidade. Vitória: EDUFES, 2017. p. 121-142.

ARAÚJO, Anna Rita Ferreira de. Os cursos superiores de formação de professores de artes visuais no Brasil: percursos históricos e desigualdades geográficas. Anais da $32^{a}$ Reunião Anual Associação Nacional de Pós-Graduação e Pesquisa em Educação (ANPEd) "Sociedade, cultura e educação: novas regulações?". Caxambu, 04 a 07 de outubro de 2009. Disponível em: <http://32reuniao.anped.org.br/arquivos/trabalhos/GT24-5360--Int.pdf>. Acesso em: 15 ago. 2018.

BRASIL. Resolução CNE/CP n. 02, de $1^{\circ}$ de julho de 2015. Diretrizes Curriculares Nacionais para a formação inicial em nível superior (cursos de licenciatura, cursos de formação pedagógica para graduados e cursos de segunda licenciatura) e para a formação continuada. Brasília, Diário Oficial [da] República Federativa do Brasil, seção 1, n. 124, p. 8-12, 02 de julho de 2015. Disponível em: <http://portal.mec.gov.br/docman/agos to-2017-pdf/70431-res-cne-cp-002-03072015-pdf/file>. Acesso em: 15 ago. 2018.

BRASIL. Decreto $n^{\circ}$ 8.752, de 9 de maio de 2016. Política Nacional de Formação dos Profissionais da Educação Básica. Brasília: MEC, 2016. Disponível em: <https://www.planalto.gov.br/ccivil_03 I_ato2015-018/2016/decreto/d8752.htm>. Acesso em: 15 ago. 2018.

BUJÁN, Federico; FRADE, Isabela Nascimento; FONSECA DA SILVA, Maria Cristina da Rosa; COHAS, Maricel Gómez de la Errechea. Investigación y formación docente em artes: miradas desde América Latina. Florianópolis: UDESC; Universidade de Playa Ancha: Selo Editorial Puntángeles, 2018.

FERNANDES, Vera Lúcia Penzo. Alterações curriculares do curso de licenciatura em artes visuais: análise de uma experiência. In: BUJÁN, Federico; FRADE, Isabela Nascimento; FONSECA DA SILVA, Maria Cristina da Rosa; COHAS, Maricel Gómez de la Errechea. Investigación y formación docente em artes: miradas desde América Latina. Florianópolis: UDESC; Universidade de Playa Ancha: Selo Editorial Puntángeles, 2018. p. 151-162.

FONSECA DA SILVA, Maria Cristina da Rosa. Formação de professores de arte e perspectivas de atuação política. In: Anais do $3^{\circ}$ Simpósio da Licenciatura em Arte Visuais da FAP e $2^{\circ}$ ENREFAEB Sul. Editora FAP, Curitiba, 2010.

FONSECA DA SILVA, Maria Cristina da Rosa; HILLSHEIM, Giovana Bianca Darolt. As políticas governamentais brasileiras e sua influência na formação docente em arte. In: inVisibilidades (Lisboa). v. 6, 2014. p. 10-21. Disponível em: <https://issuu.com/invisibilidades/docs/revista _invisibilidades_n6>. Acesso em: 15 ago. 2018.

FONSECA DA SILVA, Maria Cristina da Rosa. BUJÁN, Federico Ignacio. Políticas públicas de formação docente em artes: perspectivas em duas realidades, Brasil e Argentina. Revista GEARTE, Porto Alegre, v. 3, n. 1, p. 26-52, jan./abr. 2016. Disponível em: <http://seer.ufrgs.br/gearte>. Acesso em: 15 ago. 2018.

FRADE, Isabela. Sujeitos do conhecimento e relações comunitárias: formação docente na prática da arte relacional. In: GONÇALVES, Maria Gorete Dadalto; REBOUÇAS, Moema Martins. Modos de ser professores de Arte na contemporaneidade. Vitória: EDUFES, 2017. p. 101-120.

FRIGOTTO, Gaudêncio. A interdisciplinaridade como necessidade e como problema nas Ciências Sociais. In: Revista do Centro de Educação e Letras da UNIOESTE. v. 10, n. 01, 2008. p. 42-62.

GONÇALVES, Maria Gorete Dadalto; REBOUÇAS, Moema Martins. Modos de ser professores de Arte na contemporaneidade. Vitória: EDUFES, 2017. 
HILLESHEIM, Giovana Bianca Darolt. Um olhar para as pesquisas que abordam a formação de professores de artes visuais: caminhos percorridos e a percorrer. Dissertação de Mestrado, Programa de Pós-Graduação em Artes Visuais/CEART/UDESC, Florianópolis - SC, 2013, p. 137.

ROSA, Maria Cristina. A formação de professores de Arte: diversidade e complexidade pedagógica. Florianópolis: Insular, 2005.

SIMÕES, Vera Lúcia de Oliveira. A formação de professores de arte na modalidade EAD-UAB/UFES. In: GONÇALVES, Maria Gorete Dadalto; REBOUÇAS, Moema Martins. Modos de ser professores de Arte na contemporaneidade. Vitória: EDUFES, 2017. p. 295-312.

SOUSA, Richard Perassi Luiz de. O desafio da imagem: alternativa contemporânea para a arte nas escolas de segundo grau. 1995. 138 f. Dissertação (Mestrado) - Universidade Federal de Mato Grosso do Sul. Centro de Ciências Humanas e Sociais. Departamento de Educação, 1995. 